\section{Palmar sweating and control of danger'}

JAMES M. DABBS, JR., University of Michigan, Ann Arbor, Mich. 48108, HOWARD LEVENTHAL, University of Wisconsin, Madison, Wis. 53706, and FREDERICK W. HORNBECK, University of Califormia, Los Angeles, Calif. 90024

Palmar sweating was monitored on Ss faced with shocks over which they could exert varying control. Shocks were also varied so that some Ss could escape only after receiving shock and others could avoid shock entirely. Control-no control interacted with escape-avoidance, producing peaks in sweating when Ss could not control their escape and when they could control their avoidance. The peaks may reflect more arousal in these two conditions, or they may reflect arousal which is more localized in time.

This paper describes two experiments on helplessness and control in human Ss exposed to electric shock. Mowrer \& Viek (1948), Gibson (1957), and Weiss (1968) report the damaging effects of helplessness in the face of danger. Brady, Porter, Conrad, \& Mason (1958), on the other hand, in their study of the "executive monkey," report that having control over danger is more damaging than being helpless. These studies focused upon "stress" responses in animals, including the development of duodenal ulcers.

The present study focused upon the dependent variable of palmar sweating. Sweating is a transient and peripheral response, but one which seemed likely to vary markedly with anticipation of shock. It is related to GSR, an indicator of sympathetic arousal (Montague \& Coles, 1966). The sweat measure used here is described by Dabbs, Johnson, \& Leventhal (1968). It is scored from a count of the active sweat glands in a specially prepared fingerprint, and it can be used to track sweat changes at 20- to 30-sec intervals.

\section{EXPERIMENT 1}

Method

Subjects were 20 paid female summer students at Southern Connecticut State College $^{2}$ who volunteered to take part in a shock experiment. Each $S$ reported alone for the experiment, where she was seated at a table between a male and a female E. Two silver electrodes, the size of quarters, were taped to her forearm and a signal light and telegraph key placed in front of her. One $E$ controlled the apparatus and gave instructions. The other $\mathrm{E}$ took fingerprints for the sweat measure. S was told to place her hand on the key, wait for the signal light and simultaneous shock, and move her hand as quickly as possible. ${ }^{3}$

Half the Ss were told that they could terminate each shock by reacting quickly (control). The other half were told each shock would be the same length no matter what they did (no control). Shocks were actually fixed to last about $.4 \mathrm{sec}$ in both conditions. Each $S$ received one training shock and three low-intensity $(1 \mathrm{~mA}$ at $200 \mathrm{~V})$ and three high-intensity $(2.5 \mathrm{~mA}$ at $500 \mathrm{~V}$ ) experimental shocks in the order HLLHLH or LHHLHL. Limiting resistance of 200,000 ohms minimized effects of individual differences in skin resistance.

Shock trials were $3 \mathrm{~min}$ apart. On each trial (1) $S$ was told $90 \mathrm{sec}$ beforehand whether shock would be low or high intensity; (2) $60 \mathrm{sec}$ before the shock S placed her hand on the key, and a fingerprint was taken; (3) the signal light and shock came on, and $S$ took her hand off the key; (4) S was told to rest and a second fingerprint was taken immediately; and (5) $90 \mathrm{sec}$ later, intensity of the next shock was announced.

Each $\mathrm{S}$ was given four mean scores to represent her palmar sweating before and after low-intensity shocks and before and after high-intensity shocks.

\section{Results}

Interviews with several Ss revealed no suspicion about the procedure. Shock always terminated in less than $.3 \mathrm{sec}$ after $\mathrm{Ss}$ ' responses (RT $\vec{X}=.16 \mathrm{sec}$ ), and the situation was apparently ambiguous enough that $\mathrm{Ss}$ believed what $\mathrm{E}$ told them about their control over the shocks.

The sweat data are summarized in Table 1. A three-way mixed analysis of variance was performed, with control as a between-Ss factor and shock intensity and time (pretrial, posttrial) as within-Ss factors. The only significant effect was the Control by Time interaction $(F=4.99, \mathrm{df}=1 / 18$, $\mathrm{p}<.05$ ), reflecting different patterns of sweating in the two conditions. Ss with control tended to increase in sweating from before to after shock, while Ss with no control tended to decrease. Overall mean sweating did not differ significantly between control and no-control conditions or between low and high shock intensity.

Table 1

Mean Palmer Sweat Scores in Experiment I

\begin{tabular}{lcc}
\hline Control & \multicolumn{2}{c}{ Time of Measure } \\
\cline { 2 - 3 } $\begin{array}{l}\text { Over } \\
\text { Shock }\end{array}$ & Before Shock & After Shock \\
\hline Yes & 45 & 54 \\
No & 42 & 38 \\
\hline
\end{tabular}

\section{EXPERIMENT 2}

Method

Because there was no measure immediately before the shocks in Experiment 1, it was not possible to know whether the sweat patterns diverged after the shocks or immediately before them. Experiment 2 was set up with additional measures to determine whether differences in sweating appear before the shocks.

Also, Ss in Experiment 1 could never avoid shock entirely; they always received shock before escaping. Experiment 2 added "avoidance" conditions, in which Ss might receive no shock at all. Control-no control and escape-avoidance were combined in a 2 by 2 factorial design. ${ }^{4}$

The Ss were eight male and eight female Southern Connecticut State College students, recruited in the same manner as before. Apparatus and physical arrangements were similar to Experiment 1. Two male and two female Ss were run in each condition.

The main features of the instructions for each condition were as follows:

(A) Escape-control. "You will get a shock every time in this condition, but ... moving your hand will turn off the shock ... You can control how long the shock lasts."

(B) Escape-no control. "You will get a shock every time in this condition, and ... the shock always stays on for the same length of time ... You have no controlat all over the shock."

(C) Avoidance-control. "You may get a shock in this condition, but . . . movingyour hand will prevent shock ... You can control whether or not you get a shock."

(D) Avoidance-no control. "You may get a shock in this condition, but ... the equipment is set ... You have no control over whether or not you get a shock."

In each condition there were three trials 2 min apart. Shocks lasted approximately $.4 \mathrm{sec}$ in escape conditions, and intensity was about $1.5 \mathrm{~mA}$ at $300 \mathrm{~V}$. There were no shocks in avoidance conditions.

For each trial in each condition, (1) $\mathrm{S}$ was alerted $60 \mathrm{sec}$ before the trial and a fingerprint was taken; (2) S placed his hand on the key and started watching for the light $20 \mathrm{sec}$ before the trial, and a second fingerprint was taken; (3) the light and shock (or light only in avoidance conditions) came on and $S$ took his hand off the key; (4) a third fingerprint was taken immediately; and (5) $60 \mathrm{sec}$ later S was alerted for the next trial.

Each $\mathrm{S}$ was given three mean scores to represent his palmar sweating $60 \mathrm{sec}$ before, $20 \mathrm{sec}$ before, and immediately after the trials.

Results

The sweat data are summarized in Fig. 1. A three-way mixed analysis of variance was 


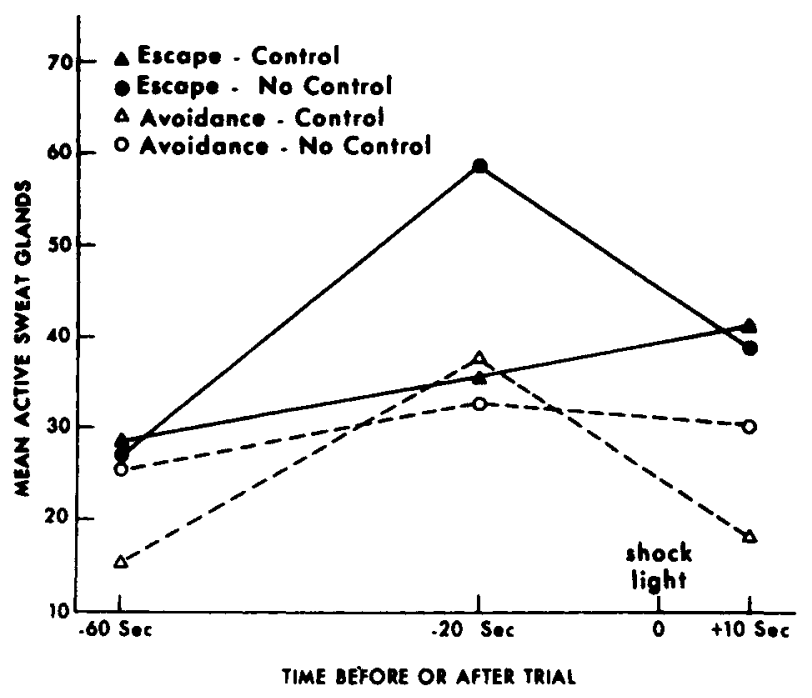

Fig. 1. Palmar sweating in Experiment 2.

performed, with control and escape-avoidance as between-Ss factors and time (60 sec pretrial, $20 \mathrm{sec}$ pretrial, immediate post trial) as a within-Ss factor.

There were two significant effects among these data. First was a main effect of time $(F=10.31, \mathrm{df}=2 / 24, \mathrm{p}<.001)$, reflecting the increase from a minute before to immediately before and after each trial. Second was a Control by Escape-Avoidance by Time interaction $(F=4.94$, df $=2 / 24$, $\mathrm{p}<.05)$, reflecting the pretrial peaks in sweating in two conditions.

The "peaks" appeared in conditions where Ss thought they would definitely receive a shock they could not control and where Ss thought they could avoid a shock by means of their own control. These data suggest that the effects of control differ in avoidance and escape conditions.

\section{DISCUSSION}

Experiments 1 and 2 do not replicate, but procedural differences may account for this. $S$ placed his hand on the key a minute before the shock in Experiment 1 and only $20 \mathrm{sec}$ before the shock in Experiment 2, so it is difficult to know whether the pretrial measure in Experiment 1 is more comparable to the first or the second pretrial measure in Experiment 2.

Experiment 1 suggests that feelings of control affect palmar sweating.
Experiment 2 suggests that the effect is not a simple one.

Peaks in sweating, presumably indicating arousal, were associated sometimes with helplessness and sometimes with control in Experiment 2. When an $S$ is shocked, the shock itself may be of primary concern. The $S$ who knows he will receive a shock may be more aroused when helpless than when he can control the length of the shock. The task of control is not difficult, and it reassures the $S$ that he can cope with the danger.

When shock can be avoided the situation is different. Now the shock itself may be of less concern, but the effort of exerting control may be greater. Control requires the $S$ to be vigilant over a longer period of time than before. Also, the consequence of error is now the onset of shock, where before it was just a slight prolonging of shock.

Another interpretation of these data would emphasize the localized nature of arousal associated with brief pretrial peaks in sweating. Arousal may drop rapidly in the conditions which are in some sense more "consistent": when S expects to be helpless in the situation and is shocked or expects to control the situation and is not shocked. In the conditions where $S$ expects to have control but is shocked, or expects to have no control but is not shocked, arousal may dissipate more slowly.

Transient palmar sweating hardly indicates great stress, but it suggests what may happen in other more stressful situations. Control is always control of something, and an individual responds both to the thing being controlled and to the element of control itself. It is a different matter to be helpless before certain danger than to be helpless before possible danger. ${ }^{5}$ Having control over certain danger is also different from having control over danger which is only possible.

\section{REFERENCES}

BRADY, J. V., PORTER, R.W.,CONRAD, D.G., \& MASON, J. W. Avoidance behavior and the development of gastroduodenal ulcers. Joumal of the Experimental Analy sis of Behavior, 1958, 1,69-72.

DABBS, J. M., JR., JOHNSON, J. E., \& LEVENThaL, H. Palmar Sweating: A quick and simple measure. Journal of Experimental Psychology, 1968, 78, 347-350.

GIBSON, J. Effects of noxious stimulation whose termination is contingent on a response and of noxious stimulation whose termination is arbitrary. Unpublished Master's thesis, Brown University, 1957.

MONTAGUE, J. D., \& COLES, E. M. Mechanism and measurement of the galvanic skin response. Psychological Bulletin, 1966, 65, 261-270.

MOWRER, O. H., \& VIEK, P. An experimental analogue of fear from a sense of helplessness. Journal of Abnormal \& Social Psychology, $1948,43,193-200$.

WEISS, J. M. Effects of coping responses on stress. Journal of Comparative \& Physiological Psychology, 1968, 65, 251-260. NOTES

1. This research was supported in part by United States Public Health Service Grants $\mathrm{CH}-00077$, CH-00265, NU-00228, and CH-00044.

2. The authors wish to thank Prof. William K. Trinkhaus for assistance in obtaining Ss and for providing lab space.

3. Repeated mood measures were obtained from $S s$ in both Experiment 1 and Experiment 2. The mood changes contributed little to an understanding of the situation, and they will not be discussed here.

4. Each $S$ was run through all four experimental conditions. Some Ss became confused toward the end of the session, and, presumably because of this, differences among conditions are obscured when all data is included in the analysis. The procedure and data are reported here only for the first condition in which each $S$ served.

5. Parenthetically, this may be relevant to some of the studies cited earlier. The helpless animals of Brady et al (1958), which showed no signs of stress, received only about one shock every $6 \mathrm{~h}$, while Weiss' helpless animals (1968), which developed ulcers, received about one shock every $3 \mathrm{~min}$. 